\title{
AVALIAÇÃO NA EDUCAÇÃO FÍSICA ESCOLAR: ANALISANDO AS EXPERIÊNCIAS DAS CRIANÇAS EM TRÊS ANOS DE ESCOLARIZAÇÃO
}

\author{
EVALUATION IN SCHOOL PHYSICAL EDUCATION: ANALYSIS OF CHILDREN'S \\ EXPERIENCES IN THREE YEARS OF SCHOOLING
}

\author{
EVALUACIÓN EN LA EDUCACIÓN FÍSICA ESCOLAR: ANALIZANDO LAS \\ EXPERIENCIAS DE LOS NIÑOS EN TRES AÑOS DE ESCOLARIZACIÓN
}

\author{
Wagner dos Santos*, Aline de Oliveira Vieira* Bruna Jéssica Mathia*, \\ Marciel Barcelos ${ }^{*}$, Juliana Martins Cassani*
}

\begin{abstract}
Palavras chave
Avaliação.

Escolaridade.

Desenho.

Educação Física.

Resumo: $O$ objetivo deste artigo é analisar o que as crianças produzem diante do ato de avaliar na Educação Física, em três anos da escolarização. Utiliza a pesquisa narrativa com sete crianças do $6^{\circ}$ ano do ensino fundamental de uma escola da Prefeitura Municipal de Serra, no Espírito Santo. Tem como fontes os diários de Educação Física produzidos pelas crianças, que contêm registros escritos e imagéticos, assim como as suas narrativas individuais orais. 0 processo de análise evidencia a potencialidade no uso dos diários como prática avaliativa longitudinal, pois as crianças sinalizam a maneira processual com que atribuem complexidade aos seus aprendizados, expressando as relações estabelecidas com os saberes da Educação Física, em três anos da escolarização.
\end{abstract}

Keywords:

Evaluation.

Educational status.

Drawing.

Physical Education.

Palabras clave:

Evaluación.

Escolaridad.

Dibujo.

Educación Física.

Abstract: This article analyzes what children produce when faced with evaluation in Physical Education in three years of schooling. It uses narrative research with seven 6th graders of a primary school in the Municipality of Serra, Espírito Santo, Brazil. Its sources include Physical Education diaries produced by the children, which contain written and image records, as well as their individual and oral narratives. The analysis points to the potential of using diaries as a longitudinal evaluation practice, since children show the procedural way in which they ascribe complexity to their learning, thus expressing the relationships they establish with Physical Education knowledge in three years of schooling.

Resumen: El objetivo de este artículo es analizar lo que producen los niños ante el acto de evaluar en la Educación Física, en tres años de la escolarización. Utiliza la investigación narrativa con siete niños del $6^{\circ}$ año de la enseñanza fundamental de una escuela del Ayuntamiento Municipal de Serra, en Espírito Santo. Posee como fuentes los diarios de Educación Física producidos por los niños, los cuales contienen registros escritos y de imagen, así como sus narrativas individuales y orales. El proceso de análisis evidencia la potencialidad en el uso de los diarios como práctica evaluativa longitudinal, pues los niños apuntan hacia la manera procesal con que atribuyen complejidad a sus aprendizajes, expresando las relaciones establecidas con los saberes de la Educación Física, en tres años de la escolarización
Universidade Federal do Espírito Santo. Vitória, ES, Brasil. E-mail: wagnercefd@gmail.com> ninna.maguinhos@gmail.com bruunamathias@hotmail.com; marcielbarcelos@gmail.com> julianacassani@gmail.com>

Recebido em: 03-10-2017 Aprovado em: 27-02-2019 Publicado em: 05-08-2019

DOI: https://doi.org/10.22456/1982-8918.76974 (c) (i) () Licence 


\section{INTRODUÇÃO}

Na área da Educação, estudos do tipo "estado do conhecimento" sobre a avaliação do ensino e da aprendizagem destacam o aumento quantitativo de pesquisas empíricas produzidas na escola e em diálogo com professores e crianças. Realizados no contexto educacional brasileiro (CALDERÓN; POLTRONIERI, 2013; GLAP, 2013) e francês (ALLAL; LOPEZ, 2005), esses trabalhos referem-se à importância de investigações longitudinais focadas sobretudo nos processos formativos das crianças.

Especificamente no campo da Educação Física, estudos de mapeamento publicados no Brasil (MELO et al., 2014; NOVAES; FERREIRA; MELO, 2014; SANTOS et al., 2018) e em países de língua inglesa (LÓPEZ-PASTOR, 2013; LORENTE-CATALÁN; KIRK, 2013) também sinalizam o maior interesse dos pesquisadores por discussões sobre a avaliação na educação básica. De acordo com os autores, apesar de os trabalhos, nos últimos 15 anos, enfatizarem a necessidade de mudanças na concepção de avaliação fundamentada no ato da medida, são tímidas as iniciativas que apresentam possibilidades concretas de práticas avaliativas formativas no contexto escolar.

Esse cenário evidencia a importância de se construir uma avaliação que considere as especificidades da Educação Física como componente curricular e, da mesma maneira, dê visibilidade à relação com o saber produzido pelas crianças em diferentes anos da escolarização. Como já sinalizam Santos e Maximiano (2013), Santos et al. (2014), Santos et al. (2015) e Santos et al. (2016), a produção de práticas avaliativas nos permite compreender os sentidos atribuídos pelas crianças aos seus aprendizados, especificamente pelo uso dos diários, fotografias, atividades pedagógicas escritas e desenhos como instrumentos da avaliação.

Os autores exploram o modo como os docentes de Educação Física têm inventariado diferentes possibilidades avaliativas, em especial os diários construídos pelas crianças. Em suas pesquisas, o diário se caracterizou como um instrumento avaliativo individual (SANTOS; MAXIMIANO, 2013) e coletivo (SANTOS et al., 2014), lugar de produção e registro das relações que as crianças estabelecem com os saberes da Educação Física, cujo objetivo é provocar uma reflexão sobre os sentidos atribuídos aos processos de ensino-aprendizagem.

Diante desse contexto, esta pesquisa se caracteriza como uma iniciativa de ampliar 0 debate sobre a avaliação da aprendizagem em Educação Física, apresentando possibilidades pedagógicas para sua ação. Fundamentados em registros produzidos pelas crianças, nosso desafio foi retornar às suas narrativas de três anos de escolarização, para que elas analisassem e estabelecessem releituras sobre as suas experiências vividas no passado e no presente, com foco no aprender nesse componente curricular. Para tanto, assumimos como objetivo analisar o que as crianças produzem diante do ato de avaliar na Educação Física, em três anos da escolarização.

Apresentamos possibilidades de mudança de entendimento sobre a avaliação, tendo em vista a perspectiva assumida pelas crianças. Com esse movimento, evidenciamos a sua compreensão sobre as especificidades da Educação Física como componente curricular e os sentidos produzidos pelas crianças em sua relação com o saber, em três anos de escolarização. 


\section{TEORIA E MÉTODO}

Assumimos a pesquisa narrativa como perspectiva teórico-metodológica para produzir e analisar as fontes. De acordo com Certeau $(2002,2006)$, reconhecer o estatuto epistemológico do narrar e ouvir histórias de vida implica considerá-lo para além de uma complementariedade ao campo textual, mas como um saber-dizer que se constitui em autoridade na produção de teorias. Em uma perspectiva que compreende as intencionalidades das crianças em narrar sobre as suas experiências avaliativas, reconhecemos que essa arte de dizer não se restringe à descrição dos instrumentos e critérios de avaliação, mas também produz efeitos e possibilidades, configurando-se tanto em rememorações das práticas cotidianas como em práticas em si.

Do mesmo modo, apropriamo-nos do conceito de Josso (2010) sobre as narrativas como práticas inscritas em um corpo "biograficamente falado". Nesse processo, compreendemos que o narrar-se permitiu às crianças, por meio da autoavaliação, a tomada de consciência de suas aprendizagens, contribuindo, no tempo histórico do agora, para o entendimento de suas singularidades individuais e coletivas.

Delimitamos, como colaboradores da pesquisa, sete crianças do $6^{\circ}$ ano do ensino fundamental (EF) de uma escola da Prefeitura Municipal de Serra no Espírito Santo (PMS/ ES). Elas foram escolhidas pelo fato de serem as mesmas que produziram os registros de um trabalho anterior, em que identificamos o uso do diário de Educação Física e do desenho como práticas avaliativas da docente (SANTOS et al., 2015).

Em 2014, essas crianças se encontravam no $4^{\circ}$ ano do $E F$, tinham entre oito e nove anos de idade e estudavam em uma escola da PMS/ES. Em 2015, a professora de Educação Física trabalhou em outra instituição de ensino da PMS/ES e, das 20 crianças que foram suas alunas em 2014, sete também se transferiram para a mesma escola. Naquele momento, elas faziam $05^{\circ}$ ano do EF e tinham entre nove a dez anos. Em 2016, ano de realização desta pesquisa, as crianças permaneceram na escola com a mesma docente. Elas cursavam o $6^{\circ}$ ano do EF, com idade entre dez e onze anos.

Essa descrição se faz relevante pela opção metodológica dos pesquisadores em convidar crianças que fossem alunas de uma mesma professora de Educação Física em três anos de escolarização consecutivos e que utilizaram o diário como registro de avaliação. Assim, voltamos às crianças no fim de 2016, com o objetivo de dar continuidade à pesquisa anterior (SANTOS et al., 2015) e compreender a relação que elas estabelecem com os seus processos avaliativos da aprendizagem, entre 2014 e 2016.

Consideramos como fontes todos os diários de Educação Física, construídos em 2014 e 2015, e as narrativas individuais orais das crianças sobre esses instrumentos de avaliação, realizadas no fim 2016. A fim de inventariar diferentes registros avaliativos, a professora de Educação Física criou um diário para que os alunos mostrassem individualmente sobre seus processos de aprendizagem experienciados nas aulas desse componente curricular.

Para elaborarem os seus diários, as crianças faziam uso da linguagem escrita e imagética, o que nos possibilitou transitar pelas diferentes formas de expressão que enredam as práticas da Educação Física. Nesse caso, tanto a escrita como os desenhos foram assumidos como narrativas, em um movimento de pesquisa que nos permitiu conhecer as formas de 
tradução de suas experiências e, ainda, possibilitou-nos compreender os sentidos que elas atribuem aos seus aprendizados.

O uso do diário se diferencia, tendo em vista a intencionalidade assumida pela professora e o momento em que foi utilizado. Mapeamos, dessa maneira, o seu emprego: a) como avaliação diagnóstica realizada no início de um trimestre, com o objetivo de planejar a prática pedagógica da professora; nele, foi identificado o que os alunos aprenderam, o que precisavam aprofundar e, ainda, o que gostariam de aprender; b) como avaliação formativa desenvolvida durante o processo, com o intuito de adequar a atuação profissional da docente; na leitura do diário, ela considerou aquilo que as crianças estavam aprendendo e os sentidos tecidos por elas aos seus aprendizados; e c) como avaliação somativa, produzida no fim do trimestre/ano letivo, com o propósito de mapear os percursos formativos dos alunos e perceber os avanços e as lacunas em seus processos de aprendizagem. ${ }^{1}$

Fundamentados nos diários, realizamos, no fim de 2016, entrevistas individuais orais do tipo narrativa (BAUER; GASKELL, 2012) com as crianças. Fomos à escola em dez dias e, nas aulas de Educação Física, convidamos as crianças, individualmente, a narrarem sobre as suas experiências de aprendizagem registradas em seus diários. Ao apresentarmos os materiais construídos por elas em 2014 e 2015, tínhamos como propósito levá-las a refletir sobre o uso do diário como instrumento avaliativo, o que seria avaliar para as crianças e os sentidos atribuídos por elas aos saberes aprendidos na Educação Física.

Nosso intuito foi potencializar as práticas avaliativas e criar ações de pesquisa que reconhecessem a relação da memória com as fontes aqui produzidas: uma coleção interminável de particularidades, constituída por situações e saberes heterogêneos "[...] cujos conhecimentos não se podem separar dos tempos de sua aquisição" (CERTEAU, 2006, p.157-158). Elas dão visibilidade à ação-reflexão-ação sobre o que se ensina e o que se aprende, mas também sobre o que se aprende com o que se ensina.

Ao mergulharmos nas narrativas das sete crianças do $6^{\circ}$ ano do $E F$, buscamos resgatar as experiências singulares e coletivas, rememoradas e compartilhadas nos diários de Educação Física e nos desenhos produzidos por elas. Nessa forma de registro, que busca evidenciar o modo como os alunos se relacionam com o saber, demos especial atenção às subjetividades encarnadas na experiência de cada praticante e suas implicações para pensarmos o estatuto epistemológico que trata a Educação Física.

Sob a perspectiva da avaliação da aprendizagem como prática investigativa contínua de professores e crianças (ESTEBAN, 2002), focalizada no saber e no ainda não saber, fortalecemos o modo de análise e produção processual das fontes, pois ele evidencia, com maior proximidade, os sinais e as pistas deixados pelas crianças sobre seus aprendizados com as práticas corporais (SANTOS, 2005; SANTOS et al., 2015). Dessa maneira, as narrativas foram assumidas não como dados, mas analisadas como produtos (CERTEAU, 2006), consequência da ação cultural das crianças no lugar/espaço da instituição escolarizada.

Para fins desta pesquisa, foram mantidos os nomes originais das crianças. Conforme previsto pelo Conselho Nacional de Saúde, elas assinaram o Termo de Assentimento Livre e Esclarecido e as suas famílias o Termo de Consentimento, autorizando o uso dos

1 No cenário da produção acadêmica, os tipos de avaliação diagnóstica e formativa se transformaram em perspectiva, como podem ser vistos, respectivamente, em Luckesi (2000) e Harlen e James (1997). 
registros. A pesquisa foi aprovada pelo Comitê de Ética da Ufes sob o número de Processo 15419913.4.0000.5542.

\section{PRÁTICAS AVALIATIVAS EM TRÊS ANOS DE ESCOLARIZAÇÃO: PROGRESSÕES DO APRENDER}

Analisamos a trajetória das práticas avaliativas produzidas pela docente e sua contribuição para os processos de aprendizagens nas aulas de Educação Física, compreendendo, nas narrativas, a produção de sentidos das crianças sobre o aprender. Assim, os diários constituíram um espaço de registro de suas aprendizagens e do modo como se relacionam com os saberes nas aulas de Educação Física, como salientam Dânia e Eduarda:

Foi interessante escrever o diário, porque eu nunca tinha feito isso antes! 0 diário é para relatar o que a gente aprendeu na prática, ver se a gente aprendeu mesmo. Eu escrevi o que aprendi, o que eu achava! (DÂNIA, entrevista, 2016).

Foi legal porque eu pude me expressar, falar do que conseguia fazer, dos meus sentimentos e sobre tudo que eu sentia na Educação Física (EDUARDA, entrevista, 2016).

As crianças reconhecem, como saberes privilegiados na Educação Física, as práticas corporais e a relação que estabelecem consigo e com os outros. Em diálogo com as teorias de Charlot (2000) sobre as relações com o saber e as figuras do aprender, compreendemos que esse componente curricular valoriza o saber de imbricação do eu em situação que ocorre no domínio de uma atividade e tem o corpo como lugar de apropriação do mundo; e o saber produzido pela distanciação-regulação, que se refere ao aprender pelos relacionamentos e situações, pelo domínio de uma relação recíproca com os sujeitos. Essa relação com o saber forma um sujeito encarnado, temporal e provido de afetividades e apropriações de valores.

Apesar de a Educação Física historicamente privilegiar os saberes de imbricação do eu em situação e de distanciação-regulação, isso não significa que ela desconsidera o saber de objetivação-denominação, cuja forma de existência se inscreve em livros, monumentos ou obras de arte. Charlot (2000) afirma que esse saber se refere à apropriação de conceitos, de fórmulas, de abstrações que se constituem em capital simbólico da humanidade. A escrita dos alunos em seus diários e seus desenhos demonstram que, no momento em que registram como se sentiram nas aulas, transformam os saberes de imbricação do eu em situação e de distanciação-regulação em objetivação-denominação. Partimos, assim, das práticas encarnadas no corpo para produzirmos os saberes de objetivação-denominação.

Esse movimento não exclui a possibilidade de os alunos sentirem um estranhamento em escrever, especificamente nos processos avaliativos produzidos na Educação Física. Alexander enfatiza: "Eu achei meio esquisito ela dar isso!" (Entrevista, 2016), como se esse saber não fizesse parte do rol dos saberes ensinados por esse componente curricular. 0 "esquisito", na visão de Alexander, refere-se ao fato de a professora ter solicitado que os alunos escrevessem nas aulas de Educação Física.

A análise dos diários evidencia como as diferentes formas de avaliar permitem às crianças dar visibilidade ao modo processual pelo qual estabelecem relação com os saberes específicos da Educação Física, autoavaliando os processos formativos. Um olhar detalhado sobre esses registros mostra as experiências de aprendizagem com a Educação Física que, 
na visão das crianças, ganham destaque quantitativo: o futebol, a ginástica, a queimada e a dança. É o que sinalizam Dânia e Lorena:

Figura 1 - Diário de Dânia no $2^{0}$ trimestre/2015

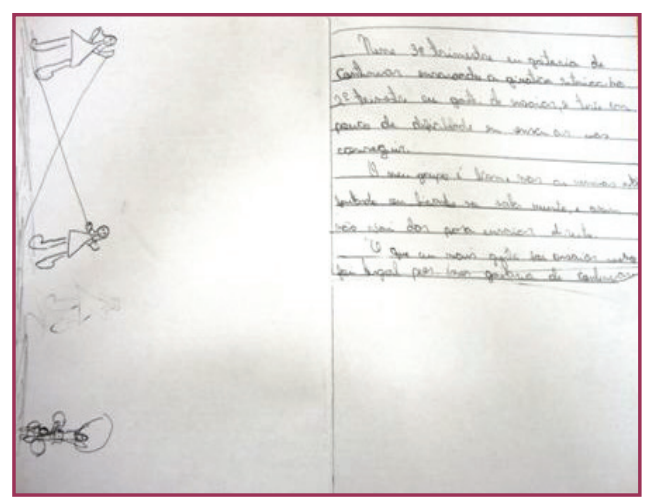

Fonte: Os autores

Legenda:

Nesse $3^{\circ}$ trimestre eu gostaria de continuar ensaiando a ginástica rítmica. № $2^{\circ}$ trimestre eu gostei de ensaiar, e tive um pouco de dificuldade em ensaiar mas conseguir.

0 meu grupo é bom. Mas as meninas estão faltando ou ficando na sala muito, e assim não vai dar para ensaiar direito.

0 que eu mais gostei foi ensaiar mesmo foi legal por isso gostaria de continuar.
Figura 2 - Diário de Lorena no $2^{0}$ trimestre/2015

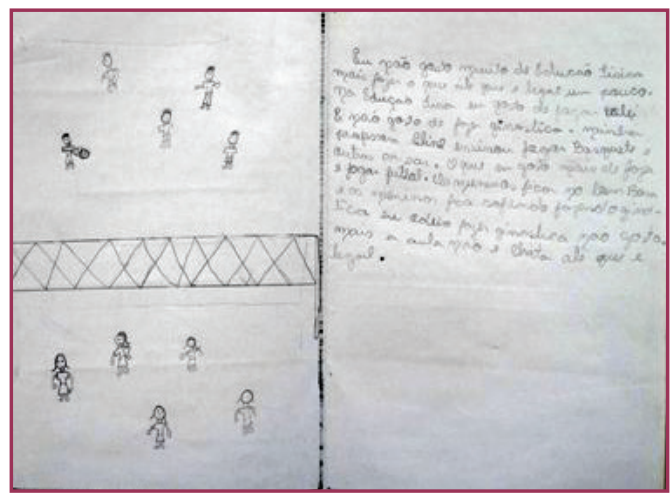

Fonte: Os autores

Legenda:

Eu não gosto muito de Educação Física mais fazer o que até que e legal um pouco. Na Educação Física eu gosto de jogar vôlei e não gosto de fazer ginástica. Minha professora Aline ensinou jogar basquete e outras coisas. $O$ que eu gosto mais de fazer e jogar futebol. Os meninos fica no bem bom e as meninas fica sofrendo fazer ginástica eu odeio fazer ginástica não gosto. Mais a aula não e chata até que e legal.

A análise das fontes evidencia a potencialidade de os processos de escrita e de desenhos transformarem as vivências das aulas de Educação Física em experiências (LAROSSA BONDÍA, 2001). ${ }^{2}$ Por meio desses registros, as crianças expressam não só que mais gostaram nas aulas, mas também aquilo que queriam aprender. Além disso, as narrativas de Dânia e Lorena nos mostram como as vivências com as práticas desse componente curricular são comuns, mas os sentidos atribuídos a elas diferenciam-se.

Dânia expressa a sua satisfação em ensaiar uma coreografia de ginástica rítmica, sinalizando ser essa a experiência que mais a tocou (LAROSSA BONDÍA, 2001) nas aulas de Educação Física. Ao dar visibilidade ao saber incorporado nas aulas, ela o faz tanto pelo manejo das fitas e dos arcos como pelo domínio desses aparelhos em relação ao espaço que ocupa, elaborando pequenas formações coreográficas, no desenho. Dânia também demonstra como se apropria do saber de distanciação-regulação, pois ela aprende ginástica rítmica pela relação estabelecida com as suas colegas, em situação. Inclusive, as limitações encontradas por ela acerca do grupo com o qual tem ensaiado, como a ausência de algumas alunas nas aulas, é o que dificulta a construção da própria coreografia.

Já Lorena não se identifica com esse conteúdo. A aluna faz questionamentos em relação às vivências dos meninos e das meninas, pois, enquanto os alunos podem jogar futebol - a prática com a qual mais se identificam -, as meninas "sofrem" ao "fazer ginástica". A insatisfação de Lorena em relação às aulas pode estar relacionada com a sua necessidade de se ver em práticas que, de fato, gostaria de experimentar, no caso, o futebol. Quando comparamos o diário produzido por ela em 2015 com aquele feito em 2014, algumas questões referentes ao que se aprende nas aulas de Educação Física já eram sinalizadas, conforme indica a Figura 3:

2 Para Larrosa Bondía (2002, p. 20), a experiência constitui aquilo que se passa ao sujeito, o que lhe acontece e o toca, um saber "[...] que se adquire no modo como alguém vai respondendo ao que vai lhe acontecendo ao longo da vida e no modo como vamos dando sentido ao acontecer do que nos acontece". 
Figura 3 - Diário de Lorena no 3ํㅡㄴimestre de 2014

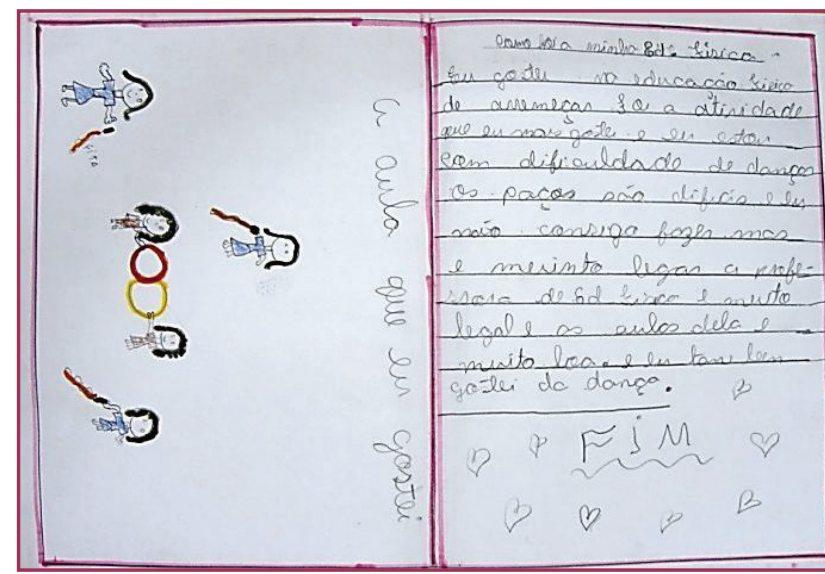

Legenda:

Como foi a minha Ed. Fisica.

Eu gostei na educação fisica de arremeçar. Foi a atividade que eu mais gostei e eu estou com dificuldade de dançar

os paços são difcís e eu não consigo fazer. mas é muinto legar a professora de Ed. Fisica e muito legal as aulas dela e muito boa. e eu tanben gostei da dança.

FIM.

Fonte: Os autores

Lorena já apresentava, em 2014, dificuldades em seus processos de aprendizagem com a ginástica rítmica, porém com outra forma de linguagem. De maneira sutil, ela rememora as suas limitações, o que não ocorre em 2015, quando, de modo contundente, afirma não gostar desse conteúdo.

Os problemas apresentados por Lorena em 2014 influenciam o modo com o qual ela se relaciona com esse componente curricular e, ao mesmo tempo, projetam as suas relações com o saber. Ganha destaque a própria natureza do saber que se ensina na Educação Física, uma vez que a dificuldade de dominar corporalmente uma prática faz com que ela, em um primeiro momento, sinalize que não a considerava "muito legal" para, um ano depois, afirmar que "odeia fazer ginástica".

O diário como instrumento avaliativo ofereceu indícios do juízo de valor estabelecido por Lorena sobre o que ela aprendeu, sinalizando ao professor a necessidade de definir o ensino de outros saberes nas aulas de Educação Física. As suas narrativas apresentaram pistas para a organização do trabalho docente, ao escrever, no diário de 2015, os seus interesses em relação àquilo que gostaria de aprender na Educação Física, reforçando uma escrita já produzida em 2014. Nesse ano, a aluna demonstra interesse em aprender práticas corporais coletivas que ela nomeia como brincadeiras de arremessar e, em 2015, ela as chama de esporte. 0 desenho de 2015 também evidencia o entendimento de Lorena sobre a movimentação dos participantes durante um jogo de vôlei, pois ela organiza um grupo de meninas e um grupo de meninos em lados opostos da quadra, situados de diferentes maneiras no espaço.

O processo de análise nos mostra a importância de assumir as narrativas das crianças como fontes avaliativas, especialmente pela capacidade de formação dos alunos na projeção das práticas e na releitura de seus aprendizados. A própria mudança de nomenclatura de "brincadeiras de arremessar" para "esporte" indica como a ação avaliativa permite ao aluno atribuir sentidos ao modo como a professora sistematiza as suas práticas de ensino, no processo de escolarização. Ao vivenciarem as práticas corporais, as crianças encontram, no uso de registros avaliativos, a possibilidade de construir seus conhecimentos e aprendizados sobre essas práticas, como é o caso da passagem da brincadeira para o esporte.

Desse modo, a avaliação se apresenta como um processo de reflexão sobre e para a ação, contribuindo para que o professor e o aluno se tornem capazes de perceber indícios, 
de atingir níveis de complexidade na interpretação de seus significados e de incorporá-los como eventos relevantes para a dinâmica de ensino-aprendizagem. Investigando, o professor direciona o seu trabalho pedagógico com o objetivo de qualificar o ensino e mediar os processos de aprendizagem, conforme as necessidades de seus alunos, individual e coletivamente consideradas (ESTEBAN, 2002; SANTOS, 2005).

Os diários produzidos pelas crianças, em sua escrita e em seus desenhos, oferecemnos pistas sobre o modo progressivo com o qual a professora ensina, mas também sobre como elas atribuem complexidade às suas aprendizagens com os saberes da Educação Física. Com o aprofundamento do conteúdo esporte, especialmente a partir de 2015, ganham destaque diferentes saberes aprendidos nesse componente curricular, como sua história, regras e noções táticas, conforme pode ser visto na aproximação das narrativas de Ruan, produzidas em 2014 e 2015:

Figura 4 - Diário de Ruan no 1ํㅡㄴimestre/2014

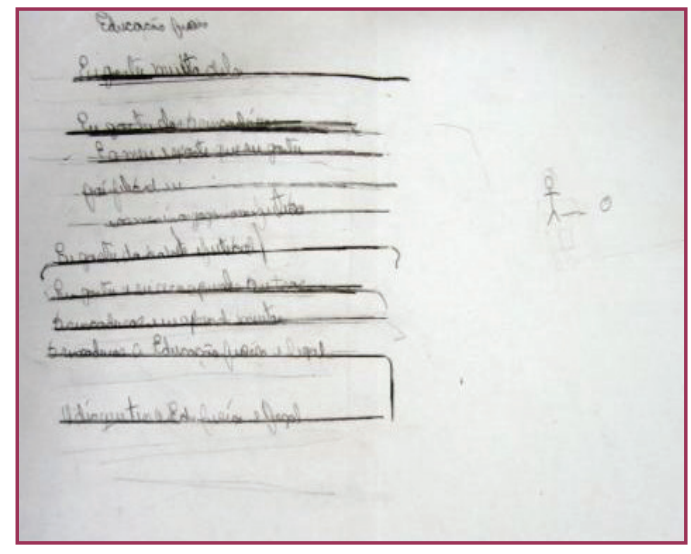

Fonte: Os autores.

Legenda:

Eu gostei muito dela

Eu gostei das brincadeiras

E o meu esporte que eu gostei foi o futebol

Os meninos jogam futebol.

Eu gostei de basquete e futebol. Eu gostei e eu cero aprender outras brincadeiras e eu aprendi muitas brincadeiras. A educação física é legal. $\mathrm{O}$ dia que tem Ed. Física e legal.
Figura 5 - Diário de Ruan no 3ํㅡㄴimestre/2015

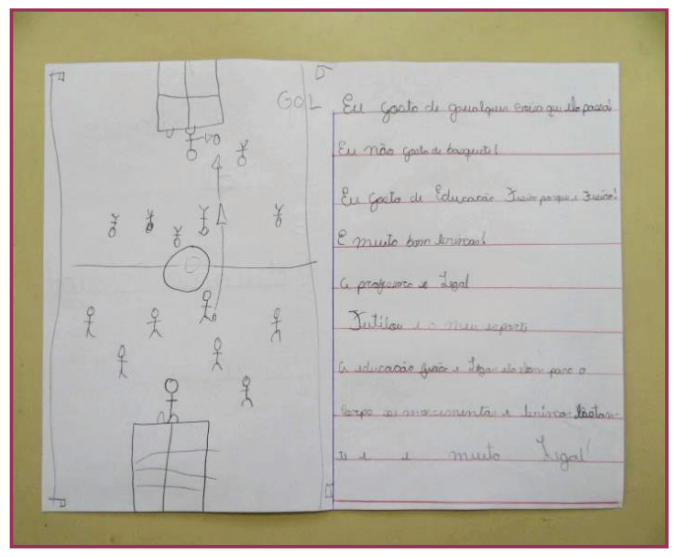

Fonte: Os autores.
Legenda:
Eu gosto de qualquer coisa que ela passa.
Eu não gosto de basquete!
Eu gosto de educação física porque é física!
É muito bom brincar!
A professor é legal
Futibou é o meu esporte. A educação física é Legau ela é bom para o corpo se movimentar e brincar bastante e e muito Legal!

Em suas narrativas, deparamo-nos com a leitura positiva que 0 aluno estabelece com a Educação Física, com a professora, com os colegas e com as próprias aprendizagens. A diferença encontrada está no desenho. Em 2014, ele coloca uma pessoa chutando a bola para o gol. Já em 2015, há a disposição dos jogadores em campo, o deslocamento da bola, em uma organização que reconhece a delimitação do campo de futebol com bandeirinhas colocadas nos escanteios e com a organização de jogadores em dois lados diferentes. Ruan nos mostra como suas aprendizagens em relação ao futebol se tornaram mais complexas, isto é, se antes ele via o futebol como uma prática realizada individualmente, em 2015 esse esporte passa a ser compreendido como uma modalidade de invasão na qual se joga em equipe, cujo objetivo é fazer o gol.

Esse modo de apresentação do futebol na Educação Física nos oferece pistas do processo de aprendizado dos alunos e fortalece a produção de imagens como forma de avaliação nesse componente curricular. A imagem, nesse caso, não exerce somente a ocupação de "[...] informar ou ilustrar, mas também de educar e produzir conhecimento" (SARDELICH, 2006, p. 459). 
Desse modo, os usos de registros avaliativos por imagens sinalizam as maneiras com as quais as crianças se biografam (JOSSO, 2000), dando sentido às suas experiências formativas com práticas corporais. Eles possibilitaram, como ressalta Marques (2010, p. 144), "[...] a reflexão sobre o trabalho pedagógico e a aprendizagem das crianças, mas também a construção de memória de um percurso, a apropriação da experiência, a reconstrução da prática". Assim, a avaliação é compreendida como ação investigativa (ESTEBAN, 2002), que permite aos professores e aos alunos interrogarem os processos de ensino e de aprendizagem, interrogando-se, ou seja, produzindo registros imagéticos de suas histórias com o aprender, evidenciando o que se aprende e o que se faz com o que se aprende nas aulas de Educação Física.

No processo de releitura dos registros imagéticos e textuais produzidos nos diários, Ruan nos mostra o que compreende como especificidades do componente curricular Educação Física. Ao reafirmar, em sua narrativa, aquilo que escreveu em seu diário - de que gosta dessa disciplina "[...] por ser física!" (RUAN, entrevista, 2016) -, ele reconhece a dimensão física de um corpo-sujeito (CHARLOT, 2009), definindo como estatuto epistêmico o saber de imbricação do eu em situação. Ele nos oferece pistas para respondermos à questão proposta por Charlot (2009, p. 237), quando nos faz a seguinte problematização: "Será que a Educação Física pode (e como?) produzir efeitos análogos sem, ao consegui-lo, perder-se na linguagem e deixar de ser uma educação física?".

Compreendemos, com isso, que a criança não aprende apenas quando lê, escreve e fala. Aprende também quando se expressa corporalmente, uma vez que o se-movimentar não pode ser considerado apenas natural, espontâneo e biológico, mas se relaciona principalmente com questões culturais, afetivas e sociais. Para Schneider e Bueno (2005, p. 40), no trabalho com a Educação Física, mais importante do que conseguir sistematizar uma explicação do que se aprendeu é vivenciar a experiência. Desse modo,

Os conhecimentos com os quais a disciplina Educação Física lida, como os esportes, jogos, danças, lutas e ginástica, são atividades constantemente submetidas a minivariações de situações de aplicação, por isso a dificuldade de expô-las integralmente em forma de enunciados. Fazer com, nesse sentido, indica o tipo de investigação que se pode desenvolver quando se busca compreender o conhecimento que os alunos e alunas conseguiram mais incorporar do que sistematizar em forma de enunciados [...] (SCHNEIDER; BUENO, 2005, p. 40).

As práticas avaliativas produzidas na Educação Física precisam dar visibilidade para a relação que as crianças estabelecem com os saberes produzidos por esse componente curricular. Nesse caso, o reconhecimento do "fazer com" estabelece a necessidade de um olhar em que se "[...] pergunta pelo domínio que os alunos possuem de determinado saber em relação aos usos que podem fazer desse conhecimento em determinada situação" (SCHNEIDER; BUENO, 2005, p.40).

Essas reflexões trazem indagações sobre o papel da Educação Física no contexto escolar, sua singularidade e significação, pois, ao lidar com a relação de imbricação do eu em situação que se centraliza na dimensão do "fazer com", ela subverte a forma escolar. A escola é lugar da palavra ou de outras formas de simbolização do mundo, do texto, dos saberes sistematizados, cujo modo de existência é a linguagem. Por isso, há valorização do "falar de" e "escrever sobre" em contraposição ao "fazer com". 
Se, por um lado, essa disciplina ressignifica o espaço escolar, por outro, tem que se adequar a ele, ou seja, ao mesmo tempo em que a Educação Física opera com as lógicas e procedimentos que oferecem fundamento à forma escolar, como é o caso da nota, também a subverte, à medida que estabelece relação do "[...] corpo-sujeito com o mundo, um mundo compartilhado com outros, uma forma incorporada de ser dono de si mesmo e de seu ambiente" (CHARLOT, 2009, p.244).

Nesse caso, as narrativas das crianças demonstram as relações que elas constroem com práticas avaliativas centralizadas na escrita, tanto na Educação Física como em outros componentes curriculares:

[...] não é a mesma coisa, porque lá [nas outras matérias] ele está falando 'escreve isso, isso e isso!', [...] e aqui no diário você escreve o que quer, o que você gostou (EDUARDA, entrevista, 2016).

[...] porque em matérias como o Português você tem que fazer, fazer conta. Já aqui [na Educação Física] você vai falar 0 que você gosta e 0 que não gosta (HELIJANE, entrevista, 2016).

Porque lá na sala tem outras coisas, muito dever de Matemática, Português, Geografia... Na Educação Física, não! São algumas coisas como jogar bola (ALEXANDER, entrevista, 2016).

Em suas narrativas, as crianças diferenciam 0 ato de avaliar na Educação Física de outras disciplinas que compõem o currículo escolar. Elas afirmam que, nos outros componentes curriculares, é necessário escrever algo fundamentado naquilo que o professor já definiu. No diário, elas expressam o que aconteceu nas aulas, as suas experiências e o que foi mais significativo nas suas relações com os saberes e com os demais colegas.

O diário, nesse caso, configura-se como um instrumento de avaliação que tem permitido às crianças registrar as suas práticas formativas e ressignificar suas experiências com as/nas aulas de Educação Física. Ele anuncia uma mudança na avaliação realizada no contexto escolar, em que assume, como ação central, o protagonismo do aluno e do professor nos processos de ensino-aprendizagem. Avaliar, desse modo, constitui-se em um constante movimento de produção e análise da própria formação, pensada individual e coletivamente. Os diários, em sua linguagem escrita e imagética, tornam-se potentes instrumentos avaliativos que dão visibilidade à voz do aluno, em uma dupla leitura avaliativa docente-discente. Eles enriquecem a discussão de como avaliar, para além da observação docente nas aulas de Educação Física.

Os diários, como instrumentos avaliativos, possibilitam ao leitor perceber a produção de sentidos sobre o que se ensina, o que se aprende e o que se faz com o que se aprende nas aulas de Educação Física. Eles se constituem como espaços para as crianças materializarem e se apropriarem dos conhecimentos no âmbito das diferentes linguagens. Esses conhecimentos, provocados pelo movimento de tradução dos saberes de imbricação do eu em situação e distanciação-regulação em objetivação-denominação, constituem a base para a construção de uma narrativa escrita e imagética, que permite a ressignificação do registro das práticas corporais, mediada pela cultura.

O diário dá visibilidade aos consumos (CERTEAU, 2002) das crianças em relação àquilo que é ensinado nas aulas de Educação Física, sinalizando como essas apropriações se diferenciam e constituem um lugar próprio (CERTEAU, 2002). Assim, os acontecimentos nas 
aulas de Educação Física são comuns a todos os alunos, mas a definição do que marca as aprendizagens, transformando-as em experiências, é individual.

Nesse processo, amplia-se 0 entendimento das crianças sobre as suas aprendizagens e sobre aquilo que elas gostariam de aprender, como evidencia o processo de releitura dos diários produzidos em 2014. É o que observamos nas narrativas de Dânia e Eduarda:

A professora mandou a gente ficar de cabeça pra baixo e, com a ajuda dela, plantamos bananeira, fizemos paredão e várias outras que eu não consigo lembrar de ginástica (DÂNIA, entrevista, 2016).

Porque eu aprendi a chutar direito, aprendi as posições que eu tenho que ficar. $\mathrm{Na}$ hora de arremessar, eu aprendi direitinho as posições que eu tenho que ficar. E foi muito legal porque de tudo aquilo se formou a brincadeira! (EDUARDA, entrevista, 2016).

Quando aproximamos as narrativas individuais orais produzidas no fim de 2016 dos registros nos diários feitos em 2014, notamos como as alunas elaboram enunciados mais complexos sobre as suas experiências. Em seu diário de 2014, Dânia narrou:

Figura 6 - Diário de Dânia no $2^{0}$ trimestre/2014

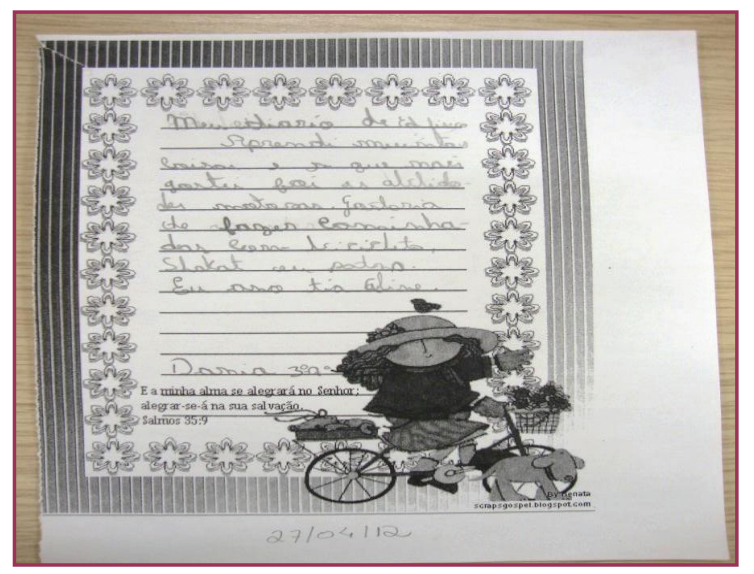

Legenda:

Meu diário de Ed. Física

Aprendi muitas coisas e a que mais gostei foi de abilidade motora Gostaria de fazer caminhadas com bicicleta, slakate patins. Eu amo tia Aline

Fonte: Os autores.

Assim, o que antes Dânia entendia isoladamente como habilidades motoras passa a ser compreendido, no momento de releitura dos diários, de maneira aprofundada e articulada com as práticas culturais historicamente produzidas. A identificação da aluna com as habilidades motoras registradas no diário de 2014 estava relacionada com a vivência de diferentes brincadeiras que remetem à parada de mãos, de acordo com a sua narrativa produzida em 2016.

Essa mesma compreensão é reforçada na entrevista de Eduarda, quando ela analisa seus diários. Conforme a Figura 7 abaixo, a aluna narrou, em 2014, que aprendeu a chutar e arremessar em situação de brincadeira, além de ter vivenciado a dança. Já em 2015, Eduarda enfatizou a ginástica rítmica como experiência que a tocou, dando visibilidade a detalhes da técnica corporal, da complexidade e de sua motivação ao produzir uma coreografia: 
Figura 7 - Diário de Eduarda no 1º trimestre/2014

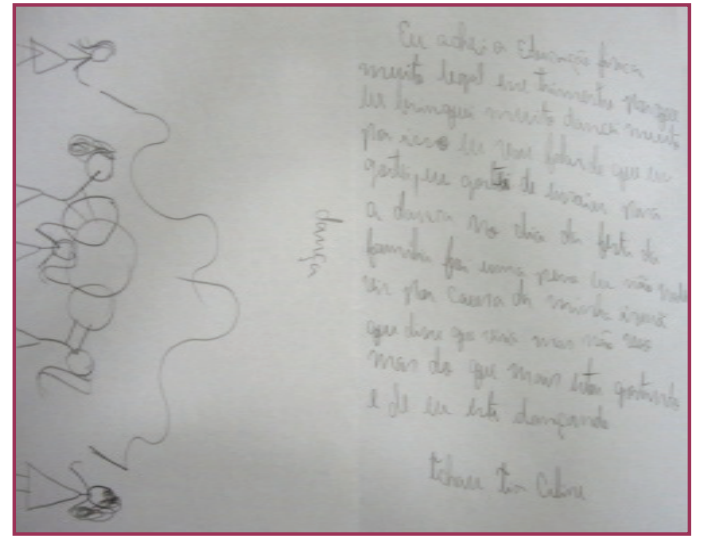

Fonte: Os autores.

Legenda:

Eu achei a educação física muito legal esse trimestre porque eu brinquei muito dancei muito por isso eu vou falar de que eu gostei, eu gostei de ensaiar para a dança no dia da festa da família foi uma pena eu não pude vir por cauda da minha irmã que disse que viria ma não veio mas do que mais estou gostando e de eu esta dançando.
Figura 8 - Diário de Eduarda no 1ํtrimestre/2015

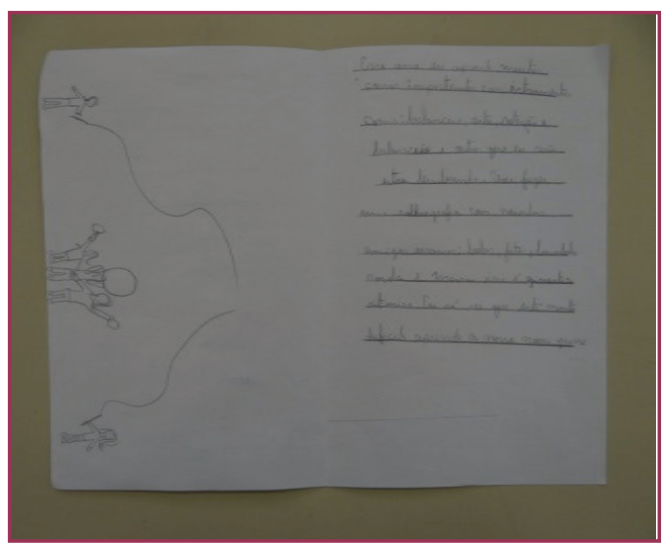

Fonte: Os autores.

Legenda:

Esse ano eu aprendi muitas coisas importantes como: balanceio, oito, rotação, balanceio e outras que não estou me lembrando. Vou fazer uma coreografia com as minhas amigas usando: bola, fita, bambolê corda e massa isso é ginástica rítmica. Eu sei que está muito difícil aprende a nossa nova pose.

Em seus diários, identificamos as trajetórias das aprendizagens de Eduarda com as práticas corporais, que avançam das habilidades motoras à dança e, por fim, à ginástica rítmica. Os seus desenhos nos mostram que, mesmo em 2014, tendo desenvolvido os movimentos que constituem a ginástica rítmica, Eduarda ainda a reconhecia como dança. Já em 2015, ela estabeleceu relação entre a técnica corporal e a música, considerando esses dois elementos como uma prática esportiva historicamente produzida, denominada ginástica rítmica.

Há, nos processos de aprendizagem de Dânia e Eduarda, a articulação dos saberes de imbricação do eu na situação com a ginástica que, em 2014, se localizava no ainda não saber (ESTEBAN, 2002), ou seja, Eduarda desenhou os elementos da ginástica rítmica, mas não a compreendia como prática corporal esportiva. O sentido produzido por Eduarda em 2014 busca aprender movimentos básicos com aparelhos ginásticos ainda na relação lúdica de "dançar com objetos". O que a marca é o fato de apresentar "o novo" aprendizado nas aulas de Educação Física para a família. Já ao final do primeiro trimestre de 2015, há uma progressão do aprender com ginástica rítmica, quando a narradora destaca detalhes sobre os componentes técnicos do esporte e seus movimentos coreográficos.

Conforme sinalizam as narrativas das crianças, as práticas avaliativas realizadas pela professora estão centralizadas nos processos de aprendizagem e aproximam-se da perspectiva avaliativa indiciária (SANTOS, 2005). Elas articulam a ideia de interrogar, interrogando-se nas aulas, ao longo de todo o processo educativo, em um fazer que leva professora e alunos a procurarem indícios do aprender e do ainda não aprender nas aulas de Educação Física. A avaliação indiciária valoriza as heterogeneidades das aprendizagens das crianças, tomando-as como elementos significativos para a ampliação dos seus conhecimentos.

Santos (2005) afirma que a prática indiciária considera os seguintes eixos para a construção dos processos de aprendizagem: o aprender a aprender (buscar novas informações); aprender a conviver (interagir com os outros); e aprender a ser (refletir sobre si próprio como aprendiz). Essas ações fazem-se presentes nas escritas dos diários das crianças e em suas narrativas individuais orais, quando rememoram as suas experiências de 
aprendizagem registradas nesse instrumento avaliativo. Nesse processo, elas evidenciam a relação que estabelecem com as práticas de ensino construídas pela docente; o modo como mobilizam as suas aprendizagens, mostrando-nos o que aprenderam e o que fizeram com 0 que aprenderam; e, ao mesmo tempo, acenam para as relações interpessoais estabelecidas com os colegas, consigo e com a professora.

O uso de registros avaliativos como o diário de Educação Física evidencia caminhos para projetar os processos da aprendizagem, levando em consideração as especificidades desse componente curricular. Em diálogo com as práticas docentes, os registros contribuem para que as crianças atribuam novos sentidos à sua relação com o saber, em um movimento que possibilita a autoavaliação dos processos de aprendizagem.

A autoavaliação se constitui como um movimento de reflexão sobre e para a ação dos processos formativos rememorados, por meio da releitura dos diários. Essa perspectiva se aproxima da proposição de Lacerda (2001) sobre a autoavaliação como experiência de si. Para o autor, cabe à autoavaliação proporcionar o processo de experiência do aluno consigo mesmo, por meio dos saberes produzidos nas interações escolares, fomentando a reflexão dos seus processos de aprendizagem e estimulando-o a novas leituras de mundo.

É preciso ainda considerar que a análise dos diários e das entrevistas, sob a perspectiva da pesquisa narrativa associada à autoavaliação, conduziu-nos a um duplo movimento, qual seja, o de considerar as fontes como práticas formativas e como práticas de investigação. A rememoração dos diários, por parte das crianças, contribuiu para a autoavaliação dos processos formativos vivenciados nas aulas de Educação Física, em três anos de escolarização e, de igual modo, forneceu as fontes que constituem esta pesquisa. Sendo assim, "[...] essas relações oferecem condições fundamentais para a ampliação do conhecimento de si e para uma outra compreensão da formação e das leituras sobre as implicações das trajetórias de escolarização" (SOUZA, 2006, p. 59).

No exercício da docência, os diários se apresentam como ferramenta que auxilia a produção do conhecimento intermediada pelos processos de ensino. Assim, a prática avaliativa potencializa tanto a releitura dos aprendizados pelas crianças quanto a forma como os objetos de interesse da Educação Física são consumidos (CERTEAU, 2002).

O processo de releitura dos diários pelos alunos sinaliza um caminho metodológico para projetarmos possibilidades de práticas avaliativas para a Educação Física, fundamentada em uma perspectiva que assume a avaliação como ação contínua de interpretação de sinais, pistas e indícios dos processos da ação docente e de aprendizagens dos alunos. Por meio dessa concepção avaliativa, damos visibilidade aos saberes aprendidos, não aprendidos e às práticas produzidas em um constante movimento de juízo consciente de valor e tomada de decisão (SANTOS, 2005).

Os sentidos atribuídos às práticas corporais, materializados em narrativas imagéticas e escritas, potencializam os processos de rememoração do que foi ensinado, levando os alunos a autoavaliar suas aprendizagens. Para isso, faz-se necessário o uso de diferentes registros avaliativos como formas singulares de cada criança expressar os sentidos com as aprendizagens por diferentes linguagens - falada, gestual, escrita, textual, desenho.

O diário, nesse caso, configura-se como um instrumento de avaliação que permite às crianças registrarem suas práticas formativas e ressignificarem suas experiências nas 
aulas de Educação Física, por meio da autoavaliação. Ele anuncia uma mudança nas práticas pedagógicas no espaço escolar, assumindo a avaliação como constante movimento de produção e análise da própria formação, pensada individual e coletivamente.

\section{CONSIDERAÇÕES FINAIS}

Os diários convidam o leitor a analisar a produção de sentidos sobre o que se ensina, o que se aprende e o que se faz com o que se aprende nas aulas de Educação Física. Eles se constituem como espaços para as crianças materializarem os conhecimentos no âmbito das diferentes linguagens e deles se apropriarem. Esses conhecimentos, provocados pelo movimento de tradução dos saberes de imbricação do eu em situação e de distanciaçãoregulação em saberes de objetivação-denominação, constituem a base para a construção de uma narrativa escrita, imagética e oral que permite a ressignificação do registro das práticas corporais.

As narrativas evidenciam dois caminhos para analisarmos a potencialidade dos instrumentos avaliativos aqui pesquisados: no primeiro, a narrativa dos diários acena para as experiências das crianças na relação com os saberes da Educação Física e para os seus interesses pessoais, demonstrando aquilo que fazem com o que aprendem; no segundo, os diários configuram ações avaliativas que permitem à professora captar os sentidos que os alunos atribuem às práticas produzidas na Educação Física, fortalecendo uma perspectiva em que a avaliação constitui ação essencial para construir o conhecimento e reorientar a prática docente.

A releitura dos diários, no tempo presente, mostrou-se potencial à medida que permitia às crianças rememorar aquilo que aprenderam nas aulas de Educação Física. Sendo assim, pesquisar com crianças em processo formativo nos anos iniciais do EF se configurou em um fazer que dá visibilidade à compreensão das crianças sobre avaliação, revelando: como aprendo? O que faço com o que aprendo?

Desse modo, o resgate da memória propiciou às crianças uma reflexão do que thes aconteceu, promovendo a ressignificação dos aprendizados inscritos em seu corpo e a releitura do modo como compreendem a sua relação com os saberes produzidos com/nesse componente curricular, pela via da avaliação da aprendizagem.

Por fim, destacamos que esta pesquisa oferece elementos para pensarmos em uma avaliação para a promoção das aprendizagens, tomando, como ponto de partida e de chegada, a produção de sentidos que as crianças elaboram com o saber compartilhado nas aulas de Educação Física. Acenamos para a necessidade de futuras pesquisas que aprofundem as bases teórico-metodológicas, permitindo a análise entre os elementos: sentidos do aprender, imagem como narrativa do praticado nas aulas, critérios avaliativos e a projeção da aprendizagem, em mais de três anos de escolarização. 


\section{REFERÊNCIAS}

ALLAL, Linda; LOPEZ, Lucie Mottier. L'évaluation formative de apprentissage: revue de publications en langue française. In: ORGANISATION DE COOPERATION ET DEVELOPPEMENT ÉCONOMIQUES. L'évaluation formative: pour un meilleur apprentissage dans les classes secondaires. Paris: OCDE, 2005. p. 265-290.

BAUER, Martin W.; GASKELL, George. Pesquisa qualitativa com texto, imagem e som: um manual prático. 10. ed. Petrópolis, RJ: Vozes, 2012.

CALDERÓN, Adolfo Ignácio; POLTRONIERI, Heloisa. Avaliação da aprendizagem na educação básica: as pesquisas do estado da arte em questão (1980-2007). Revista Diálogo Educacional, v. 13, n. 40, p. 873-893, set./dez. 2013.

CERTEAU, Michel de. A escrita da história. 2. ed. Rio de Janeiro: Forense, 2006.

CERTEAU, Michel de. A invenção do cotidiano: 1. artes de fazer. 15. ed. Petrópolis: Vozes, 2002.

CHARLOT, Bernard. Da relação com o saber: elementos para uma teoria. Porto Alegre: Artes Médicas, 2000.

CHARLOT, Bernard. Ensinar a educação física ou ajudar o aluno a aprender o seu corposujeito? In: DANTAS JÚNIOR, Hamilcar Silveira; KUHN, Roselaine; RIBEIRO, Sérgio Dorenski Dantas. Educação física, esporte e sociedade: temas emergentes. São Cristóvão: Editora da UFS, 2009. v. 3, p. 231-246.

ESTEBAN, Maria Teresa. 0 que sabe quem erra? Reflexões sobre avaliação e fracasso escolar. 3. ed. Rio de Janeiro: DP\&A, 2002.

GLAP, Graciele. Avaliação na/da educação infantil: Estado da Arte 200-2012. 2013. 199 f. Dissertação (Mestrado em Educação) - Programa de Pós-Graduação em Educação, Universidade Estadual de Ponta Grossa, Ponta Grossa, 2013.

HARLEN, Wynne; JAMES, Mary. Assessment and learning: differences and relationships between formative and summative assessment. Assessment in Education: Principles, Policy \& Practice, v. 4, n. 3, p. 365-379, 1997.

JOSSO, Marie-Christine. Experiências de vida e formação. São Paulo: Cortez, 2000.

LACERDA, José Luiz. Fundamentos para a auto-avaliação como "experiência de si" na prática pedagógica da educação física escolar. 2001. 214 f. Dissertação (Mestre em Educação Física) - Programa de Pós-Graduação em Educação Física, Universidade Gama Filho, Rio de Janeiro, 2001.

LARROSA BONDÍA, Jorge. Tremores: escritos sobre experiência. Belo Horizonte: Autêntica, 2014.

LÓPEZ-PASTOR, Victor Manuel; KIRK, David; LORENTE-CATALÁN, Eloisa. Alternative assessment in physical education: a review of international literature. Sport, Education and Society, London, v. 18, n. 1, p. 57-76, 2013.

LUCKESI, Cipriano. A avaliação da aprendizagem escolar. São Paulo: Cortez, 2000. 
MARQUES, Amanda Cristina Teagano. A construção de práticas de registro e documentação no cotidiano do trabalho pedagógico da educação infantil. 2010. $384 \mathrm{f}$. Tese (Doutorado em Educação) - Faculdade de Educação, Universidade de São Paulo, São Paulo, 2010.

MELO, Luciene Farias et al. Produção de conhecimento em prática avaliativa do professor de educação física escolar: análise das escolhas metodológicas. Pensar a Prática, v. 17, n. 1, p. 278-294, jan./mar. 2014.

NOVAES, Renato Cavalcanti; FERREIRA, Marcos Santos; MELLO, João Gabriel de. As dimensões da avaliação na educação física escolar: uma análise da produção do conhecimento. Motrivivência, v. 26, n. 42, p. 146-160, jun. 2014.

SANTOS, Wagner dos. Currículo e avaliação na educação física: do mergulho à intervenção. Vitória: Proteoria, 2005.

SANTOS, Wagner dos; MAXIMIANO, Francine de Lima. Avaliação na educação física escolar: singularidades e diferenciações de um componente curricular. Revista Brasileira de Ciências do Esporte, v. 35, n. 4, p. 883-896, out./dez. 2013.

SANTOS, Wagner dos et al. Avaliação na educação física escolar: construindo possibilidades para a atuação profissional. Educação em Revista, v. 30, n. 4, p. 153-179, out./dez. 2014.

SANTOS, Wagner dos et al. Avaliação na Educação Física Escolar: reconhecendo a especificidade de um componente curricular. Movimento, v. 21, n. 1, p. 205-218, jan./mar. 2015.

SANTOS, Wagner dos et al. A relação dos alunos com os saberes nas aulas de educação física. Journal of Physical Education, v. 27, p. 27-37, 2016.

SANTOS, Wagner dos et al. Avaliação em Educação Física Escolar: trajetória da produção acadêmica em periódicos (1932-2014). Movimento, v. 24, n. 1, p. 09-22, jan./mar. de 2018.

SCHNEIDER, Omar; BUENO, José Geraldo. A relação dos alunos com o saber compartilhado nas aulas de Educação Física. Movimento, v. 11, n. 1, p. 23-46, jan./abr. 2005.

SOUZA, Eliseu Clementino. Arte de contar e trocar experiência: reflexões teórico-metodológicas sobre história de vida em formação. Revista Educação em Questão, v. 25, n. 11, p. 222-39, jan./abr. 2006. 


\section{Apoio:}

Conselho Nacional de Desenvolvimento Científico e Tecnológico (CNPq); Fundação de Amparo à Pesquisa e Inovação do Espírito Santo (Fapes) e Coordenação de Aperfeiçoamento de Pessoal de Nível Superior - Brasil (CAPES) - Código de Financiamento 001. 